Volume 6, Issue 4, October 2021, pp. 299 - 315

DOI: $10.23917 /$ jramathedu.v6i4.14269

p-ISSN: 2503-3697, e-ISSN: 2541-2590

\title{
Chess, visual memory and geometric transformations
}

\author{
Jorge Jhonattan Castellanos Sosa ${ }^{1 *}$, Francy Karina Maldonado Aguilar ${ }^{2}$ \\ ${ }^{1}$ Huelva University, Spain \\ ${ }^{2}$ National Pedagogic University, Colombia \\ *Corresponding author: jorgejhonattan.castellanos@alu.uhu.es
}

\begin{tabular}{|c|c|}
\hline ARTICLE INFO & ABSTRACT \\
\hline $\begin{array}{l}\text { Article history: } \\
\text { Received: } 28 \text { April } 2021 \\
\text { Revised: } 18 \text { July } 2021 \\
\text { Accepted: } 22 \text { July } 2021 \\
\text { Published online: } 11 \\
\text { September } 2021 \\
\text { Published regularly: October } \\
2021\end{array}$ & $\begin{array}{l}\text { This work shows how playing chess creates capacities in the student such } \\
\text { as increasing visual memory. This helps to classify information in an } \\
\text { orderly manner in the mind and contributes to a better understanding of } \\
\text { geometric transformations such as displacements, turns and similarities. } \\
\text { This was done with a mixed technique (Quantitative and Qualitative), } \\
\text { starting with a structured questionnaire that was applied to } 487 \text { students. } \\
\text { A case study was carried out with two students (one with and the other } \\
\text { without notable chess skills) in two schools in Bogotá-Colombia, with the } \\
\text { aim of understanding chess as a tool that can help the teacher to teach } \\
\text { mathematics. In the quantitative part, data were collected by a structured } \\
\text { questionnaire, and in the qualitative part, recordings and transcripts } \\
\text { were made of what the two students reported in the case study. So, } \\
\text { favorable results were achieved for students who usually play chess, } \\
\text { because they show a great capacity for visual memory (in the long and } \\
\text { short term) that contributes to a more optimal learning of displacements } \\
\text { and similarities in the Cartesian plane. This research shows a powerful } \\
\text { tool (chess) that can be used in the teaching of mathematics, thanks to the } \\
\text { skills and concepts that are generated in the experience with the game. }\end{array}$ \\
\hline
\end{tabular}

(C) 2021 Universitas Muhammadiyah Surakarta

\section{Introduction}

This research was carried out with a mixed technique (qualitative and quantitative) where quantitative data were acquired with a structured questionnaire for students with good chess skills (SGCS onwards) and those with limited chess skills (SLCS onwards) from two schools in Bogotá- Colombia. What was obtained in the questionnaire is contrasted with the possible understanding of certain chess situations in factors such as omission, distortion, perseverance, rotation, displacements, sizes (Benton, 1974) as types of errors and successes typical of visual memory. Then a case study was carried out with two students from different schools and different chess skills (SGCS and SLCS) that was applied in two parts. The first was an introduction to the geometric transformations already mentioned, together with its manipulation in GeoGebra, which contributed to its visual memory (for being a visual software). As a second part, an activity was proposed so that the students could identify these transformations. With the help of the recordings of what they manifested, it was possible to find verbal processes that showed the use of visual memory and the understanding of geometric concepts.

To cite this article:

Sosa, J., \& Aguilar, F. (2021). Chess, visual memory and geometric transformations. JRAMathEdu (Journal of Research and Advances in Mathematics Education), 6(4), 299-315. https://doi.org/10.23917/jramathedu.v6i4.14269 
Thus, playing chess helps the formation of mental concepts, which can be interpreted as a mental operation that allows us to understand how the experiences learned are reduced to a set of manageable conceptual categories (Paas \& Ayres, 2014). A basic example of these conceptual categories can be the identification of the chess pieces or the board, but other more complex ones can be the understanding of space in some chess game, the lines of action of the pieces, the general and specific understanding of certain positions, tactical issues, etc.

Likewise, it is necessary to inquire about didactic games that help to enhance the learning of mathematics, and contribute to non-mechanical memorization mental schemes (Subia, 2020). For this reason, it is important to look at these mental schemes to generate valid connections that generate new knowledge. Thus, the specific objective of this research is to examine and compare the visual memory of a group of students with and without chess skills with respect to the identification of geometric transformations.

\section{State of the Art}

Current works in chess, visual memory and geometric transformations have different aspects that help to better understand each of these concepts separately. An example of this is exposed in ICME 13 where considerations on visuospatial reasoning are shown (Kaiser, 2017), such as the need to generate a good visual memory in students (Giofrè, Mammarella, Ronconi \& Cornoldi, 2013), since this would help to more easily capture the information in the learning. It is also important to include classroom activities such as games, practical situations and different technological tools because this has been shown to improve visual reasoning and understanding of concepts in different areas (Sinclair, Bussi, de Villiers, Jones, Kortenkamp, Leung \& Owens, 2017). Thus, chess is a very powerful tool because it can help improve geometric understanding through its visual experience (Ferreira \& Palhares, 2008). On the other hand, tools such as GeoGebra are excellent resources due to their visual dynamism (Owens, 2015).

Kadunz and Yerushalmy ( $\underline{2015})$ answer important questions about visualization in mathematics teaching and learning, for example: what is the role of visualization within the disciplines of mathematical knowledge? What visual tasks can foster creativity that lead to meaningful mathematical knowledge? Are there types, qualities and hierarchies of visualization and visual abilities? These questions highlight the importance of visualization that can interfere with issues such as geometric transformations when using chess as the main tool, because chess has capabilities such as the development of visual memory, spatiality, logic, among others (Blanco, 2020). Likewise, the works on chess focus mainly on the mathematical modeling of the game (Ganguly, Leveling \& Jones, 2014), but another large number diverts the gaze of how this game helps to improve the cognitive abilities of the players, on topics such as the identification of regular figures (octagons or other polygons) through the movement of the pieces and their connectivity with others (Subia, $\underline{2020}$ ).

\section{Theoretical Framework}

The work of education goes beyond the transmission of knowledge, something that is still commonly seen in some educational centers in many countries (Blanco, 2020). However, it is convenient that teachers can introduce new elements in their work so that students understand in greater depth certain concepts that will serve them in their educational and personal development. In this way, chess helps develop abstract reasoning abilities thanks to the discovery of patterns (Ferreira \& Palhares, 2008) that help to solve chess situations. This would help the teaching of various mathematical concepts such as in the field of geometry, by the visual memory intervened (Paas \& Ayres, 2014). 
Chess helps develop increased academic performance in all subjects. This is due to the growth of perception, spatio-temporal orientation, abstract reasoning and logicalmathematical thinking (Taymur \& Velásquez, 1998; Ferreira and Palhares, 2008). On the other hand, Ferguson (1995) points out faculties such as organizational skills, imagination, the development of reasoning, and as a main point, the ability to memorize, which is one of the most important faculties that can be acquired by storage and reproduction of representations (Pacheco, 2020).

These cognitive schemes (Chi, Glaser, Rees \& Steinberg, 1982) are used to store and organize knowledge by incorporating or fragmenting multiple elements of information into a single element with a specific function. People who regularly play chess have broader mental structures and general concepts where they can accommodate information. So, when required, they can easily fall back on such general structures and concepts, for example, they can quickly search their mental databases of endings when they are close to checkmate. This increases their ways of learning thanks to the experience with the game, which improves as they play more and more (Jeffers, Osorio \& Guevara, 2020).

The latter belongs to long-term memory or unlimited memory (Paas \& Ayres, 2014) that Kant (2007) defines as judicious memory, in which a system is memorized while preserving its linked parts. So, if one of these parts is forgotten, we could remember anything keeping in mind the connection of that omitted part with others that are still preserved in memory (Pacheco, 2020). This is not about memorizing a large amount of information at the same time, but a process of organization and remembering that comes from experience.

But this memorization process does not happen instantaneously because short-term memory must be used for it to occur (Alloway, Gathercole \& Pickering, 2006). Information always passes through short-term memory (it is the main memory corridor), and through experience flows into long-term memory. Its characteristics are to generate and maintain representations of the information input, and to search for memory traces already saved with new information to be able to relate and understand it. The same occurs with visual long-term memory (VLTM) and visual short-term memory (VSTM) (Fukuda \& Vogel, 2019). Because the VLTM can store an almost infinite amount of visual information (Brady, Konkle, Alvarez \& Oliva, 2008; Standing, 1973), and the VSTM is the filter of the VLTM, because it performs a coding process to save the new information. So, Fukuda \& Vogel (2019) mention that the VSTM predicts the "bandwidth" of the VLTM, because the more information the VSTM supports, the more capacity the VLTM will have.

It is important to note that visual short-term memory (VSTM) expands thanks to experience (natural stimuli). This happens because by regularly doing a memorization process, it must increase its capacity because it will need certain information instantly (Ericsson, Patel \& Kintsch, 2000). This is how chess masters can remember chess positions much better than less common players (Chase \& Simon, 1973). In addition, some works by Anders Ericsson (Gong, Ericsson \& Moxley, 2015; Ericsson \& Polson, 1988) show that chess players use memory transfer mechanisms where they make mental correlations between the types of pieces, their color, their spatial proximity, and attack and defense relationships, which help to more easily remember any position or visual fragment. Thus, they manifest a chess semantics (Gong, Ericsson \& Moxley, 2015) that helps to remember any position in any order, all this thanks to the experience one has with the game (Chase \& Simon, 1973).

Not all the information we want to remember is encrypted. As already mentioned, the VSTM is limited, therefore, on average a person can temporarily store three to four representations of objects in short time intervals (Giofrè, Mammarella, Ronconi \& Cornoldi, 
$\underline{2013}$ ). Benton (1974) generated a visual retention test (BVRT) (Sivan, 1992) taking into account the ability to measure VSTM and VLTM to evaluate subjects with possible cognitive complications (Steck, 2005), although also it has been extended to other fields such as education, not only to measure cognitive impairment, but also the visual memory capacities of students (Snow, 1998). The test has a reliability of 0.85 (Cronbach's alpha) and a validity between 0.79 and 0.84 (Manna, Alterescu, Borod \& Bender, 2011).

The VSTM and VLTM have a very important attribute which is the imagination. As Ferguson (1995) had already said, the imagination is the faculty of intuition without the presence of the mental object that contains both fantasy and memory. This is something beneficial for education because it helps to understand various topics such as numerical, spatial or geometric concepts such as transformations in the plane (Pacheco, 2020). In addition, if the errors given by Benton (1974) are observed, it can be established that the last three would be related to rotations, displacements and similarity of plane figures (Marmolejo \& Vega, 2012).

On the other hand, to analyze the level of geometric abstraction of the students, Van Hiele (1986) categories was used, which explains (Table 1) that the understanding of geometric transformations (Jaime, 1993) can be categorized and interpreted as follows way:

Table 1

Categories of understanding of geometric transformations according to Van Hiele (1986) Level Description

1. Global consideration of

2. Analysis (consideration of the movements through its components)

3. Classification (relationship between properties, understanding approaches) the movements

Recognition of the size and shape of figures. Identification and execution of movements with auxiliary tools (GeoGebra). Use of elementary vocabulary and empirical visual properties to understand geometric transformations, such as saying that there are "equal figures" in displacements, "turns" in rotations, or "large or small lengths" with respect to the similarity of figures. Visual descriptions and tending to resemble them with familiar elements.

Make explicit use of the elements of the transformations (centers, coordinates, angles, lines, measures). Determination of the specific elements and properties that make up a transformation. Performing composition of transformations. Use of vocabulary and geometric notation typical of geometric transformations. Perceive properties of geometric objects. Describe objects through their properties (no longer just visually).

Describe objects and figures in a formal way. Understand the meanings of the definitions. Recognize how some properties are derived from others. and Establish relationships between properties and their consequences. Fully of understand the compositions of transformations. Decompose a transformation. Simplify the compositions. Formally assimilate the definition of transformations.

4. Formal Deduction (total Make deductions and proofs. Understand the axiomatic nature of its deductive thinking) properties. Take full formal tests.

Thanks to this classification (Table 1), it is possible to understand the different levels that students can reach with respect to geometric transformations in the plane. Students who have more experiences with geometric transformations will develop a more elaborate understanding of them, reaching an increasingly higher level (Van Hiele, 1986). These experiences lead to internalize concepts and mental schemes that often reduce the burden of VSTM (Paas \& Ayres, 2014). 
The chess player not only generally remembers his games taking into account similar positions (Ganguly, Leveling \& Jones, 2014), but he also pays attention to particular details that help to classify his information, such as endings, sacrifices, material advantage, the positionality. In addition to the lines of action or active zones, which are the set of accessible squares where a piece can be moved from its particular position. An example of these lines of action is the squares, triangles, hexagons and irregular figures that are formed between the chess pieces thanks to their connectivity (Ferreira \& Palhares, 2008). The lines of action arise in situations of attack, defense or "X-rays" (lines of action through which the enemy pieces pass, and that help to think with greater tactical depth), which are internalized in mental schemes in the VLTM, with the help of the experience and visualization of each game (information that passes through the VSTM).

It is important to highlight the importance of the game and its components, coming to think of a curricular adaptation of this as occurs in countries such as Cuba, Russia or the United States (Subia, 2020; Pawilen \& Manuel, 2018), to take advantage of its qualities and generate students with higher cognitive attitudes such as those already indicated. Stimulating new neural connections (Blanco, 2020) intertwine geometric, numerical, logical, spatial knowledge, in addition to social development. This means that once these networks are connected, there is a production of new knowledge, so chess helps make this permanent (Ferguson, 1995).

\section{Research Methods}

The research was developed in two phases, the first quantitative and the second qualitative. First, a structured test (https://youtu.be/4TwR NkAyyg, https://forms.gle/CuBS3YQnrd7zaF8M8) was applied in two schools in Bogotá-Colombia, (San Juan de Dios Bilingual School and La Estrellita School) to obtain quantitative data about visual memory (BVRT adaptation), and involvement with chess. Then, a case study was carried out (Cohen, Manion \& Morrison, 2017), that was recorded and examined with two students (one with good chess ability and the other not), referring to their identification and interpretation of geometric transformations as turns, displacements and similarities.

The BVRT consists of three equivalent forms, but only one of them was applied. This consisted of 10 visual elements (cards or images). Most of the items included three geometric shapes presented along a horizontal plane, which made the test particularly sensitive to visual perception failures (Sivan, 1992). This work focuses on the form of short-term visual memory management in which each card was exposed for 10 seconds. Then there is a waiting time of 15 seconds, which at the end, the person is asked to select between four possible options which was the one you saw (10 seconds). Thus manifesting the "bandwidth" of the VSTM, and the capacity of the VLTM. The score obtained for each card was 1 (correct) or 0 (incorrect) so the final result was the sum of the correct answers. It is important to highlight the types of errors that occurred since this evidenced the deficiencies in visual memory that the qualitative analysis entailed for the examinees. These were omission (total or partial forgetting of elements), distortion (in terms of the shape of the larger, shorter or crooked figures, sides and / or angles), perseverance (memory bias due to figures from previous cards), rotations (turns of one, several or all figures), displacement (translation of card elements) and size errors (making similar figures) (Steck, 2005). This is how the last three belong to geometric transformations, and the first three are identified as errors because they do not involve any transformation.

This was applied to 487 students between the ages of 11 and 18, from grades 6 to 11 of school (Colombia) equivalent to ESO and Baccalaureate (Spain), with $360(73.92 \%)$ from 
La Estrellita School, and 127 (26.07\%) of the San Juan de Dios Bilingual School, with a total number of people of 487 (see Table 2). This group was chosen because it is a stage in which students are more aware of their actions and processes, unlike the initial cycles.

Table 2

Total number of people per course in the applied test

\begin{tabular}{cc}
\hline Course & Number of people \\
\hline $6^{\circ}$ & 44 \\
$7^{\circ}$ & 84 \\
$8^{\circ}$ & 94 \\
$9^{\circ}$ & 114 \\
$10^{\circ}$ & 92 \\
$11^{\circ}$ & 59 \\
\hline Total & 487 \\
\hline
\end{tabular}

In the test there was a question about how good the student was considered with respect to the game of chess with a Likert scale from 1 to 4 (Manna, Alterescu, Borod \& Bender, 2011), with 1 being the lowest and 4 the highest. Previously, it was explained to the students that if they were considered to have very good chess skills, they could be between level 3 and 4, but otherwise they could be classified between 1 and 2 (this according to their experience with the game). So, the students who chose 1 and 2 were grouped as SLCS and those who chose 3 and 4 were classified as SGCS in order to be able to make conjectures regarding the values that would be obtained with the test (see Table 3):

Table 3

Results obtained in the Likert question asked

\begin{tabular}{ccc}
\hline Likert Scale & Number of students & $\%$ \\
\hline 1 & 217 & 44.55 \\
2 & 129 & 26.48 \\
3 & 85 & 15.45 \\
4 & 56 & 11.49 \\
Total & 487 & 100 \\
\hline
\end{tabular}

Table 3 showed the frequencies of students for each option of the Likert question formulated. This is how it can be seen that 346 students were classified as SLCS (71.04\%) and 141 as SGCS (28.95\%).

All the test questions had four answer options, of which one was correct and the other three intentionally had the errors defined by Benton (1974), so that in the test there were five options for each type of error. Thus, the amount of errors was equitable in the test with respect to each type of error defined by Benton.

The case study was with two 8th grade students, both 13 years old, but belonging to different schools, Diana (San Juan de Dios school) and Vanesa (Salesian school), the first category being 4 in chess (SGCS), and Vanesa category 1 (SLCS), according to the aforementioned Likert question. This is to demonstrate if the data obtained in the test and the hypotheses raised would be particularly true, or if there could be certain discrepancies.

This was applied in two parts, both of 60 minutes with a waiting time of 20 minutes to apply the second. In the first, using the dynamic geometry software GeoGebra, the understanding of some geometric transformations (turns, displacements, similarities) was 
developed using an understandable basic geometric language. In this, actions such as manipulating the GeoGebra constructions were carried out in order to internalize the concepts raised. In addition to answering some questions such as what geometric elements should be taken into account in rotations, displacements and similarities? Why? What happens to the initial figure at the end of the rotation, displacement and similarity, still has its initial properties, which ones?

- Rotation: Students were taught a construction in GeoGebra (https://www.geogebra.org/classic/h4sn3ca3) that showed rotations of plane figures that students could manipulate to understand and internalize the transformation. It is important to clarify that the names of each of the points always appeared with a different color and shape to better appreciate the turns. In addition, these could be carried out taking into account the degrees and the direction of rotation.

- Displacement: it has to do with the translation in the plane, noting the existing congruence between the initial figure and the final figure. So, the students were asked to observe and execute movements of certain figures in GeoGebra (https://www.geogebra.org/classic/srwprmpp), taking into account the displacement vector, its position in the plane and its shape to be done.

- Size: here the students observed and built in the software (https://www.geogebra.org/classic/dqr4jubb) plane figures similar to an initial (minor and major), so that they could identify their elements and properties.

The second part dealt with the identification of the transformation that took place in the comparison of an initial card and with a final one, showing some of the three mentioned transformations. It contained 9 tiles of which 3 were initial cards and 6 were transformations applied to these preliminary cards. So, the students had to look at an initial figure for 10 seconds and after 15 seconds they were shown one of the cards where there was a transformation corresponding to that figure (there were 2 transformations for each original figure), thus they had to resort to your visual memory to answer what kind of transformation was applied to achieve this result. This happened individually, and their responses were recorded and transcribed to identify the use of their memory in their expressions, words and actions.

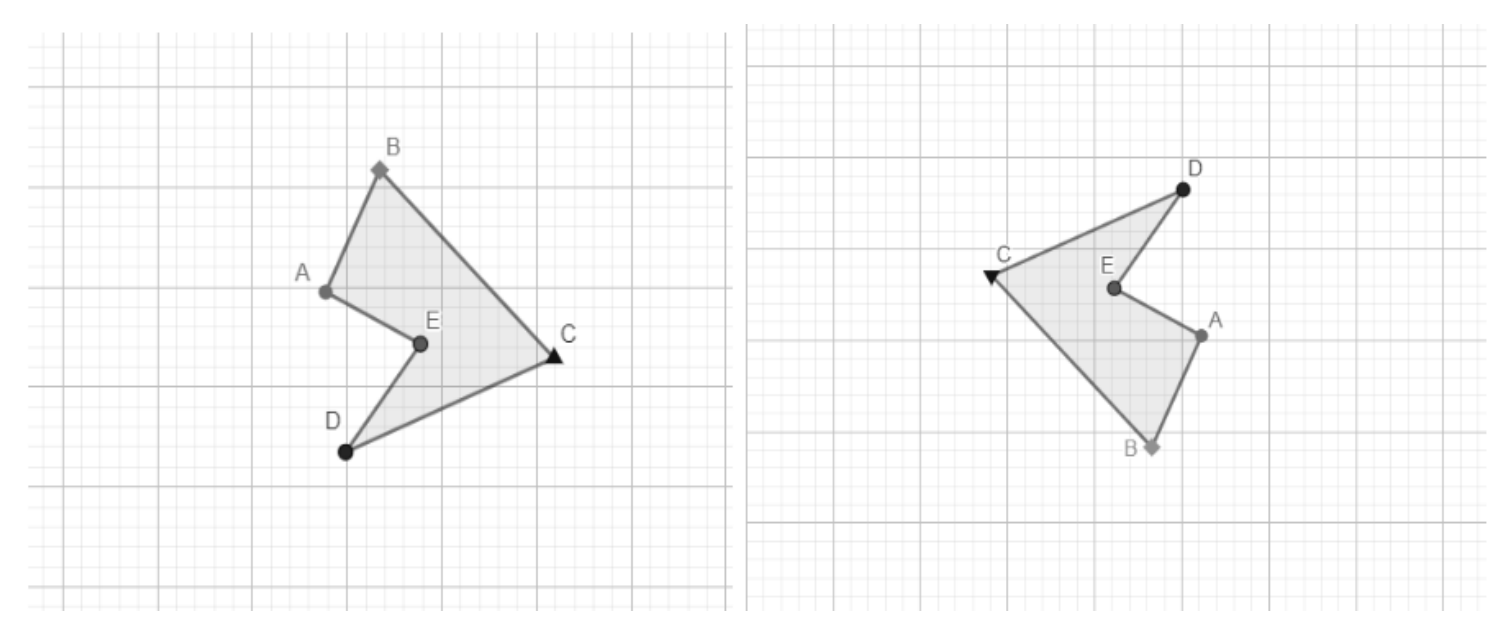

Figure 1. Example of initial figure (left) and transformation card (right).

\section{Results and Discussion}

Tables 4 and 5 show the total number of hits and misses for the SLCS and SGCS: 
Table 4

Total number of hits and misses for SLCS

\begin{tabular}{ccc}
\hline Question & Hits & Misses \\
\hline 1 & 337 & 9 \\
2 & 326 & 20 \\
3 & 310 & 36 \\
4 & 223 & 123 \\
5 & 185 & 161 \\
6 & 98 & 248 \\
7 & 124 & 222 \\
8 & 145 & 201 \\
9 & 151 & 195 \\
10 & 125 & 221 \\
\hline Total & 2024 & 1436 \\
$\%$ & $58.49 \%$ & $41.5 \%$ \\
\hline
\end{tabular}

Table 5

Total number of hits and misses for SGCS

\begin{tabular}{ccc}
\hline Question & Hits & Misses \\
\hline 1 & 140 & 1 \\
2 & 136 & 5 \\
3 & 118 & 23 \\
4 & 87 & 54 \\
5 & 95 & 46 \\
6 & 82 & 59 \\
7 & 75 & 66 \\
8 & 30 & 111 \\
9 & 28 & 113 \\
10 & 89 & 52 \\
\hline Total & 880 & 530 \\
$\%$ & $62.41 \%$ & $37.58 \%$ \\
\hline
\end{tabular}

Thus, there is a higher percentage of correct answers for the SGCS compared to the SLCS, with a difference of $3.92 \%$ (Tables 4 and 5). But, despite the small disparity, it is also possible to observe the difference in percentages between correct answers and errors for each of the classifications, with $16.99 \%$ for students who do not play very well and $24.83 \%$ for the others students. Therefore, the students who play chess were less mistaken than the SLCS.

However, when applying the T-test for independent samples in the SPSS statistical program to the errors obtained by the SLCS and SGCS, a bilateral significance (assuming equal variances) of 0.177 is found. This being greater than 0.05 , so there would not be There will be very significant differences between the groups compared. However, their means are not very close to each other, being 4.15 and 3.76, respectively, so that, on average, the SGCS are less wrong than the other group. Likewise, thanks to the 
aforementioned tool, a bilateral significance is obtained in the hits of 0.188 , so there are not such significant differences either, however, the means show on average more hits for the SGCS (6.24) than for the SLCS (5.85).

On the other hand, the frequencies and percentages for each type of error are identified (Table 6 and 7), obtaining the following:

Table 6

Number of failures and their percentages for each type of error for SLCS

\begin{tabular}{lcc}
\hline Type of error & Frequency & $\%$ \\
\hline Omission & 390 & 27.15 \\
Distortion & 285 & 19.84 \\
Perseveration & 138 & 9.61 \\
Rotation & 144 & 10.02 \\
Displacement & 239 & 16.64 \\
Size & 240 & 16.71 \\
\hline Total & 1436 & 100 \\
\hline
\end{tabular}

Table 7

Number of failures and their percentages for each type of error for SGCS

\begin{tabular}{lcc}
\hline Type of error & Frequency & $\%$ \\
\hline Omission & 72 & 13.58 \\
Distortion & 68 & 12.83 \\
Perseveration & 141 & 26.60 \\
Rotation & 121 & 22.83 \\
Displacement & 57 & 10.75 \\
Size & 71 & 13.39 \\
\hline Total & 530 & 100 \\
\hline
\end{tabular}

When observing the bilateral significance between the two groups, assuming equal variances (thanks to the SPSS), it is observed that there are significant differences in omission, perseveration, rotation and displacement with values of 0.0001 (for the first three) and 0.014. On the other hand, distortion and size do not show such significant differences with values of 0.06 and 0.112 respectively (greater than 0.05 ).

Thus, possibly the visual memory of chess players contributes less to perseveration and rotation, and more to omission and displacements. Therefore, it is important to clarify why this happens speaking from chess and the position of visual memory, linking to geometric transformations:

\section{Omission}

The results could show that thanks to chess, skills can be acquired in terms of not forgetting a piece that is submerged in the board (Ferguson, 1995). It is very important because when this happen a checkmate or some valuable loss can be prevented. But the case occurs in which the player can omit some piece that is not in explicit action, and it does not interfere with the calculations of some fundamental piece: 


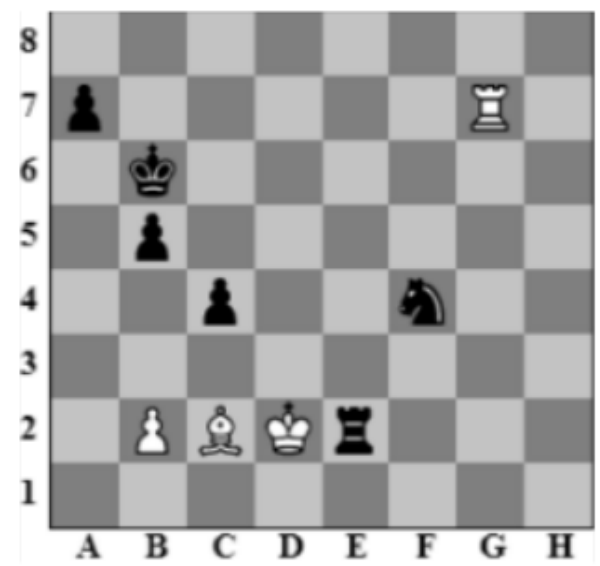

Figure 2. Pawns A7 and B5 are not directly related to the attack on the white king, so if the chess player needs to remember the position, he will probably take into account the pieces of the main attack (knight, rook, C4 pawn) with more detail.

Omission is a type of error about geometric transformations because it can be associated with the forgetting of elements such as points or lines of an initial figure with respect to a final one (Alloway, Gathercole \& Pickering, 2006). So, if the student is able not to forget an element when performing any of these geometric actions, he will have a null omission (very good), and if he neglects an element, he will have an error that would grow according to the elements he forgot.

\section{Distortion}

Possibly the data obtained with the test show that the SGCS can perceive minimal changes in a particular position because the details of the pieces (their position) and their geometric relationships (between the pieces) are important or future calculations will be wrong (Ferreira \& Palhares, 2008). That is why the player can easily distinguish the relationships between his pieces. That is, if there is a triangle between three pieces, and one piece moves, the new triangle that is formed must be considered. Therefore, SGCS are sensitive to conceive modifications between the pieces. These connections are made up of lines of action or active zones (Ganguly, Leveling \& Jones, 2014).

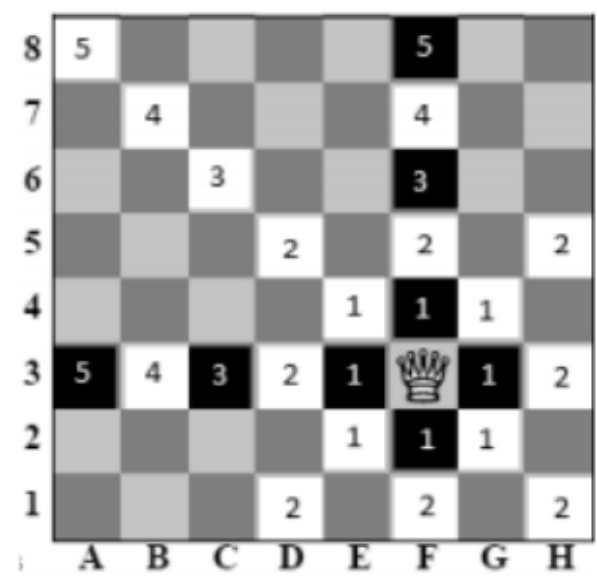

Figure 3. Lines of action of a Queen in F3.

\section{Perseveration}

As the chess player has his mental database thanks to his experience with the game, he has formed generalizations in his head (Ganguly, Leveling \& Jones, 2014), so in certain 
positions he will resort to this information. Thus, a chess player shows a great memory capacity (Schneider \& Shiffrin, 1977). It is a double-edged sword that showed significant differences in the test, since the SGCS student will regularly take into account the positions that he has already seen to remember an immediate one, so it is more common for him to get confused.

\section{Rotation}

Possibly the large percentage of errors obtained by SGCS is related to the fact that they usually take into account a global position of the game and cannot perceive a minimum change of rotation in their visual memory. The closest thing is when you analyze the perspective of the opponent's movements to understand and make the proper calculations by mentally turning the board $180^{\circ}$. So, it can be inferred that they do not usually perform mental rotations, and therefore they would not correctly identify rotations in the plane (Marmolejo \& Vega, 2012).

\section{Displacement}

The translation of the chess pieces causes their lines of action not to change. For example, the movement of the knight always takes into account 8 positions to which it can move forming an octagon (Subia, 2020). Wherever the knight moves, the octagon will maintain its shape. Of course, if the knight is on any edge of the board, it will have movements that it will not be able to make. This is an argument that supports the data obtained by the SGCS.

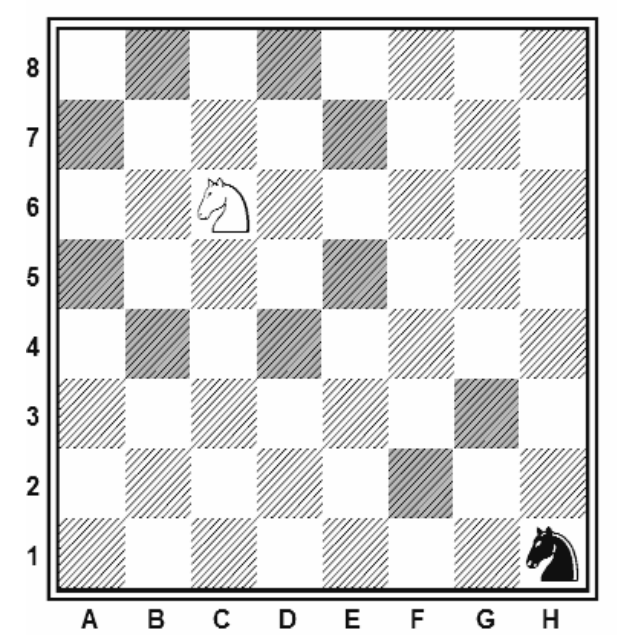

Figure 4. Octagon of movement of the white knight, and restriction of the edge of the board for the black knight.

Size

There were not very considerable differences between the two groups (SLCS and SGCS), however, it is important to mention the advantages that SGCS can have regarding the similarity of plane figures. There are geometric relationships such as the rule of the square (Subia, 2020), which helps to know if a pawn can be captured by the enemy king Thus, the player establishes proportions between the geometric figures intervened to make correct calculations. This is just an example that supports the percentage obtained by the SGCS. 


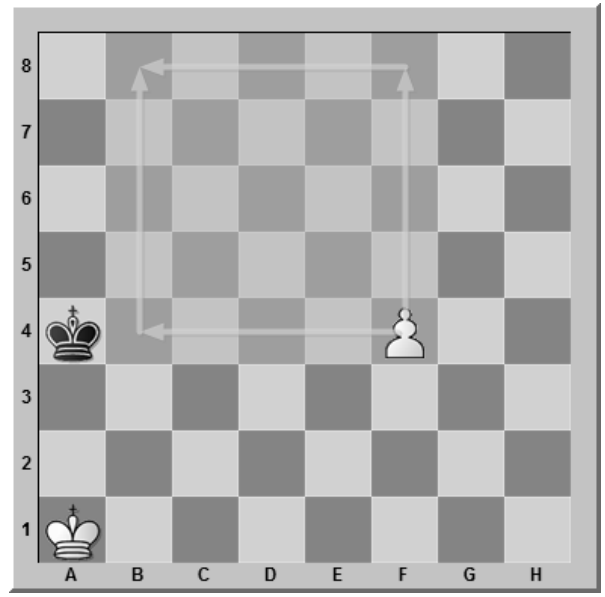

Figure 5. For each movement of the white pawn, a smaller and smaller square will be formed, if the enemy king gets inside he will be able to capture the pawn.

Thus, it is possible to perceive the relationship between what was obtained in the test with the possible chess capabilities of SGCS, and its relationship with the geometric transformations and the types of errors mentioned by Benton (1974). So, it is possible to complement what has been obtained with the case study shown below.

The case study

In the case study, the recordings helped to understand the memory processes that the students did to respond, which resulted in important verbal processes. Diana indicated the type of geometric transformation based on the elements that she recognized with GeoGebra. For example, this was said by her when she had to identify a displacement:

"... in that image there is a displacement because the figure is the same, nothing has changed, I see it the same, also in what we did (in GeoGebra) I remember that it simply moved from one place to another, and that is what I see."

Or when she had to identify a similarity, she mentioned that:

"... the displacements and sizes that you showed us (speaking to the teacher) are very similar because the figure does not change, you just have to look very closely at the cards you show us and remember what we did, that's why I say that this is the same figure but bigger ... "

This explicitly shows that the student uses the word "remember" to refer to what she saw in the explanation with GeoGebra, showing the use of her working memory (Alloway, Gathercole, \& Pickering, 2006). In addition, direct relationships with her VLTM are evidenced thanks to her VSTM (Fukuda \& Vogel, 2019) because she knows that there is a relationship between displacements and similarities because the figure always points to the same place. Showing that she has made a relevant classification of concepts in her longterm memory, for what she did in the first part of the activity with GeoGebra. Thus, there is a memory mental scheme (Subia, 2020; Paas \& Ayres, 2014) in which if the student does not remember the exact definition of any of the transformations, she can bring to her memory visual data that will help to remember what she made in GeoGebra. In addition, in this case the relationship between displacements and sizes was established (Pacheco, $\underline{2020}$ ) that would be part of the judicious memory (Kant, 2007), because a relationship was memorized while preserving its related parts.

A qualitative evaluation was also made to the students to know their Van Hiele (1986) classification for geometric transformations (Jaime, 1993) according to the language they used, and the relationships they managed to take into account So, Diana is at 
Level 1 because she used elementary vocabulary to describe visual properties about the geometric transformations shown on the cards. But, she could not reach Level 2 because she could not determine the specific properties of each transformation, although she managed to establish certain relationships between them (as she did with displacement and size). She much less would be classified as Level 3 because she does not describe geometric transformations or their elements in a formal way, and she does not understand them in depth either.

However, this is what Diana said when she had to identify a $360^{\circ}$ rotation where the figure remained the same in size and direction:

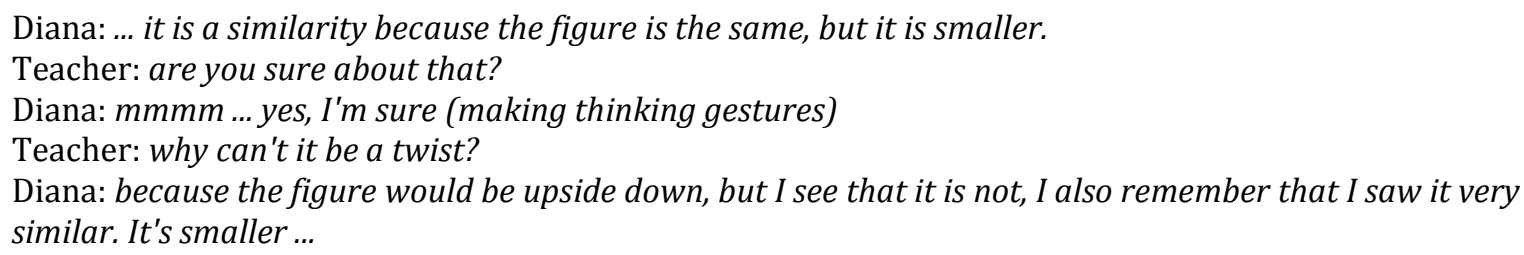

It can be seen that the student is convinced that the resulting transformation is a similarity, which can be taken as an imaginative error of complete rotation (Ferguson, 1995). However, classificatory neural connections are manifested (Blanco, 2020) that link what she worked on the geometric transformations with the relationships that she established between them, due to the characteristics of the figures after applying some transformation. Vanesa for her part could indicate a better answer:

Teacher: what transformation was applied? (Showing the card to Vanesa)

Vanesa: .... (thinking) ... it's a rotation.

Teacher: why is this so?

Vanesa: Because the figure is the same, I don't see that it is a displacement because it did not change place and it is not a similarity either because it is not bigger or smaller.

Teacher: Why is it a rotation?

Vanesa: because when we moved the figures in GeoGebra, sometimes they would arrive at the same place. I don't know, but I think it is...

Like Diana, Vanesa also used her visual memory (VSTM) to identify the type of transformation applied because she did not say a random solution, but she took a moment to analyze and say her answer. She also made deductions to discard two of the transformations and think about the complete turn. Thus, it could be said that she also generated mental schemes that helped to understand the geometric transformations (Chi, Glaser, Rees \& Steinberg, 1982). However, it is not possible to know if these schematics are completely part of her VSTM because she only takes into account what happened with the GeoGebra, maybe it takes into account things that she has worked on in her school or just uses her logic to make deductions (Fernandez, 2016). On the other hand, he fails to fully explain his argument why it is a rotation, so it could be inferred that the bandwidth of his VSTM is not very large.

In addition, according to the qualitative evaluation of classification of the level of Van Hiele (1986), Vanesa is in Level 1 because like Diana she uses elementary vocabulary to describe visual properties about the geometric transformations shown on the cards, which occurred with $360^{\circ}$ rotation. As she also indicated empirical properties of geometric transformations, she would not be at Level 2 because she did not use a language proper to geometric transformations, and much less at Level 3 because she did not use geometric formality, nor at Level 4 because she did not demonstrate knowledge of the axiomatic nature of the geometric transformations intervened. This was also manifested when she had to identify a resemblance: 
Vanesa: ... I know it can be a turn like the one before (previous quote) or a displacement because I see the same figure, I remember that it had the same number of sides, but I choose the displacement.

Teacher: ... and why can't it be a resemblance?

Vanesa: Because it is the same figure I saw before, just as it is.

Clearly more arguments are missing to indicate why it is a displacement. It only indicates that it can be this by the number of sides or that it is the same figure that you saw before, but it does not mention things like the shape or the dimension of this. This reinforces the reasoning that possibly her bandwidth is much lower than Diana's because she does not have clear and precise arguments to support her response, so her VSTM and VLTM would be low capacity (Fukuda \& Vogel, 2019). A global consideration of the transformations is also taken into account (Jaime, 1993), which would be another argument as to why it is in Van Hiele's Level 1 (1986).

It is important to note that both students used elementary language to argue their answers about the transformations that occurred. In addition, there is a recognition of the elements intervened more precisely by Diana, since she also generated associations for some of the properties of the figures. Vanesa, on her part, managed to identify several, but at times she could not correctly associate it with her responses. That is why both would be found in Level 1 defined by Van Hiele (1986) where some elements of the figures are taken into account in a general way and are expressed with informal language. In addition to the use of empirical visual properties to understand the transformations, such as when they say flip (turn) or figures larger or smaller than others (similarities). Diana would be closer to Level 2 because she takes into account more relationships between the transformations, better arguments, and the activity failed to a lesser extent ( 1 failure out of 6$)$. On the other hand, Vanesa would be at Level 1 because she does not make a correct classification mental of the geometric elements present (Jaime, 1993), and has flaws in his arguments, also in the test he failed 2 out of 6 . It should not be forgotten that the use of GeoGebra helped the students' visual memory largely due to the dynamic form of the software, thus it is important to highlight the use of visual situations to enhance learning (Owens, 2015; Van Hiele, 1986; Jaime, 1993).

\section{Discussions}

It is important to highlight that playing chess helps to develop several intellectual areas in the student, such as having a lower Omission (good visual memory of the elements of a system) or a correct interpretation of the Displacements in the Cartesian plane (which can help the spatial location of the student). Therefore, it can be a very good tool in education because it contains useful processes such as visual memory (Blanco, 2020), which can be worked on and channeled towards knowledge such as geometric transformations, logic, probability or spatiality, among others. This is how games help to acquire previous mathematical (as well as social or intellectual) concepts that can be developed in a very assertive way when working, which contributes to a more meaningful learning than part of the experience (Taymur \& Velásquez, 1998; Ferreira \& Palhares, 2008).

Although no significant differences were found between students with different chess abilities concerning errors and correct answers, they could be found in the types of errors (Benton, 1974). So, Perseveration and Rotation are items where Students with good chess skills fared worse. This is how it can be deduced that the game does not develop all the desired areas related to visual memory. So, some elements must be reinforced in students if chess is taken as a didactic tool to enhance the teaching of geometric transformations. This is how the game alone does not help to develop a concept, because the teacher will 
always be needed as a companion in the student's educational process to direct their abilities.

Thanks to the classification of Van Hiele (1986) and what was observed in the case study, it is possible to see that both students are at Level 1 in terms of understanding the geometric transformations worked on. However, Diana presented more advances than Vanessa due to her way of using a more precise language of the description of the transformations. In addition, to taking into account accurate comparisons between the intervened transformations, something in which Vanesa did not advance as much. So, learning is a dynamic process that develops from the informal to the formal level through the construction of some basic prior knowledge (Pirie \& Kieren, 1994), concepts that are obtained thanks to chess.

On the other hand, it is necessary to expand the research in terms of the number of students, to determine the fulfillment of the hypothesis that students with good chess skills would have better results than students with limited chess skills. However, Diana's capacity for visual memory and interpretation of geometric transformations, and the significant data obtained with the test, show great progress in responding to this hypothesis, so we could be facing a powerful tool that can be take advantage of mathematics education for its positive results in terms of learning concepts.

\section{Conclusions}

The students surveyed in this research who never played chess, could have played other types of games (such as checkers, soccer, tangram or Tetris), which helped to understand certain geometric elements thanks to visual memory. So, the geometric positions that can be seen in soccer, or the experience of playing Tetris could influence the test results, because chess is not the only game that helps to reinforce visual memory. However, this work shows that knowing the game of chess intensifies the components of visual memory, imagination, logical connections, and geometric understanding over a broad spectrum. This contributes to a positive evolution of the brain by understanding geometric concepts thanks to visual memory, without neglecting the use of GeoGebra that also contributed to it.

It is important to mention that in the case study the errors of omission, perseverance and distortion are not mentioned since they are not about geometric transformations, but about visual errors. Possibly an adaptation of this work can be made where the students are drawn, and thus categorizable errors can be seen with these deficiencies.

\section{Acknowledgment}

I thank the educational centers where I applied the research, as well as the people who supported me to carry it out.

\section{Bibliography}

Alloway, T.P., Gathercole, S. E. \& Pickering, S. J. (2006). Verbal and visuospatial short-term and working memory in children: are they separable? Child Development, 77(6), 1698-1716. https://doi.org/10.1111/j.1467-8624.2006.00968.x

Benton, A. (1974). Revised Visual Retention Test. Clinical and Experimental Applications 4th edition, Psychological Corporation. New York.

Blanco, J. (2020). El ajedrez como herramienta pedagógica: contextualización y fundamentación de los elementos psicopedagógicos. Capablanca, 1(2), 14-30 
Brady, T. F., Konkle, T., Alvarez, G. A. \& Oliva, A. (2008). Visual long-term memory has a massive storage capacity for object details. Proceedings of the National Academy of Sciences, 105(38), 14325-14329. https://doi.org/10.1073/pnas.0803390105

Chase, W. G. \& Simon, H. A. (1973). The mind's eye in chess. In Visual Information Processing (pp. 215-281). Academic press.

Chi, M., Glaser, R., \& Rees, E. \& Steinberg, R. J. (1982). Advances in the psychology of human intelligence. Expertise in problem solving. In R. Sternberg (Ed.) (pp. 7-75).

Cohen, L., Manion, L. \& Morrison, K. (2017). Research methods in education (pp. 440-456). Routledge.

Ericsson, K. A., Patel, V., \& Kintsch, W. (2000). How experts' adaptations to representative task demands account for the expertise effect in memory recall: Comment on Vicente and Wang (1998). Psychological Review, 107(3), 578-592. https://doi.org/10.1037/0033-295X.107.3.578

Ericsson, K. A. \& Polson, P. G. (1988). An experimental analysis of the mechanisms of a memory skill. Journal of Experimental Psychology: Learning, Memory, and Cognition, 14(2), 305-316. https://doi.org/10.1037/0278-7393.14.2.305

Ferguson, R. (1995). Resumen sobre Investigaciones del Ajedrez y su Impacto en la educación. Director Ejecutivo American Chess School. Fundación Rotaria de Panamá.

Fernández, J. (2006). Memory and perception: Remembering snowflake. THEORIA. Revista de teoría, historia y fundamentos de la ciencia, 21(2), 147-164. https://doi.org/10.1387/theoria.534

Ferreira, D. \& Palhares, P. (2008). Chess and problem solving involving patterns. The Mathematics Enthusiast, 5(2), 249-256.

Fukuda, K. \& Vogel, E. K. (2019). Visual short-term memory capacity predicts the "bandwidth" of visual long-term memory encoding. Memory \& cognition, 47(8), 14811497. https://doi.org/10.3758/s13421-019-00954-0

Ganguly, D., Leveling, J. \& Jones, G. J. (2014, July). Retrieval of similar chess positions. In Proceedings of the 37th international ACM SIGIR conference on Research \& development in information retrieval (pp. 687-696). https://doi.org/10.1145/2600428.2609605

Giofrè, D., Mammarella, I. C., Ronconi, L. \& Cornoldi, C. (2013). Visuospatial working memory in intuitive geometry, and in academic achievement in geometry. Learning and Individual Differences, 23, 114-122. https://doi.org/10.1016/i.lindif.2012.09.012

Gong, Y., Ericsson, K. A., \& Moxley, J. H. (2015). Recall of briefly presented chess positions and its relation to chess skill. PLoS One, 10(3).

https://doi.org/10.1371/journal.pone.0118756

Jaime Pastor, A. (1993). Aportaciones a la interpretación y aplicación del modelo de Van Hiele: la enseñanza de las isometrías del plano. la evaluación del nivel de razonamiento (Order No. U607169). Available from ProQuest Dissertations \& Theses Global (1525360907).

Jeffers-Duarte, B., Osorio-Curbelo, F. \& Guevara-Torres, M. (2020). Capacidades Físicas que deberí-an desarrollar los ajedrecistas en el alto rendimiento. Capablanca, 1(1), 55-70. Retreived from http://200.14.55.139/index.php/Ajedrez/article/view/7

Kadunz, G. \& Yerushalmy, M. (2015). Visualization in the Teaching and Learning of Mathematics. In The Proceedings of the 12th International Congress on Mathematical Education (pp. 463-467). Springer, Cham. https://doi.org/10.1007/978-3-319$\underline{12688-341}$

Kaiser, G. (2017). Proceedings of the 13th International Congress on Mathematical Education: ICME-13. Springer Nature. 
Kant, I. (2007). Anthropology from a Pragmatic Point of View (1798). In R. B. Louden (Ed. and trans.), Anthropology History and Education (pp. 227-429). Cambridge: Cambridge University Press.

Manna C.B.G., Filangieri C.M., Borod J.C., Alterescu K. \& Allison Bender H. (2018). Benton Visual Retention Test. In: Kreutzer J.S., DeLuca J., Caplan B. (eds) Encyclopedia of Clinical Neuropsychology. Springer, Cham. https://doi.org/10.1007/978-3-319$\underline{57111-91110}$

Marmolejo Avenia, G. A. \& Vega Restrepo, M. B. (2012). La visualización en las figuras geométricas: Importancia y complejidad de su aprendizaje. Educación matemática, 24(3), 7-32.

Owens, K. (2015). Visuospatial reasoning: An ecocultural perspective for space, geometry and measurement education. New York: Springer.

Paas, F. \& Ayres, P. (2014). Cognitive load theory: A broader view on the role of memory in learning and education. Educational Psychology Review, 26(2), 191-195. https://doi.org/10.1007/s10648-014-9263-5

Pacheco Acosta, H. L. (2020). Kant on Empirical and transcendental functions of memory. eidos, (32), 103-134. https://doi.org/10.14482/eidos.32.193

Pawilen, G. T. \& Manuel, S. J. (2018). A Proposed Model and Framework for Developing a Curriculum for the Gifted in the Philippines. International Journal of Curriculum and Instruction, 10(2), 118-141.

Pirie, S., \& Kieren, T. (1994). Growth in mathematical understanding: How can we characterize it and how can we represent it?. In Learning Mathematics (pp. 61-86). https://doi.org/10.1007/BF01273662

Schneider, W. \& Shiffrin, R. M. (1977). Controlled and automatic human information processing: I. Detection, search, and attention. Psychological review, 84(1), 1. https://doi.org/10.1037/0033-295X.84.1.1

Sinclair, N., Bussi, M. G. B., de Villiers, M., Jones, K., Kortenkamp, U., Leung, A. \& Owens, K. (2017). Geometry education, including the use of new technologies: A survey of recent research. In Proceedings of the 13th international Congress on Mathematical Education (pp. 277-287). Springer, Cham. https://doi.org/10.1007/978-3-319$\underline{62597-318}$

Sivan, A. B. (1992). Benton Visual Retention Test (5th ed.). Psychological Corporation. San Antonio.

Snow, J. H. (1998). Clinical use of the Benton Visual Retention Test for children and adolescents with learning disabilities. Archives of Clinical Neuropsychology, 13(7), 629-636. https://doi.org/10.1016/S0887-6177(97)00098-X

Standing, L. (1973). Learning 10000 pictures. The Quarterly journal of experimental psychology, 25(2), 207-222. https://doi.org/10.1080/14640747308400340

Steck, P. H. (2005). A revision of AL Benton's Visual Retention Test (BVRT) in two parallel forms. Archives of clinical Neuropsychology, 20(3), 409-416. https://doi.org/10.1016/j.acn.2004.09.009

Subia, G. S. (2020). Treasure Chess: Worthy Contributions of the Game in the Lives of Student Champions. The Normal Lights, 14(1).

Taymur, M. \& Vázquez, I. (1998). El Ajedrez Educativo Como Materia Formativa Esencial en edad Escolar. España: Comunicación presentada en el congreso de Madrid.

Van Hiele, P. M. (1986): Structure and insight. A theory of mathematics education. (Academic Press: Londres). 